\title{
The Modeling Processes Exploitation by Pavement Management System in Slovakia
}

\author{
M. Decký, M. Kováč*, J.Čelko \\ Department of Highway Engineering, University of Žilina, Žilina, Slovak Republic \\ * Corresponding author: kovac@fstav.uniza.sk
}

\begin{abstract}
Road evenness is one of the basic factors of pavement quality. It represents not only the characteristic of the road serviceability, but also road safety and comfort. Longitudinal unevenness causes traffic discomfort and a danger of wheel-pavement interaction decreasing.

Listed aspects were taken into account for an analysis of classification levels in the frame of the Slovak Pavement Management System. The simulations of different boundary conditions during pavement surface diagnostics were oriented above all to the response of unevenness to the vehicle and to the ride comfort consequently. On the other hand, an effect of unevenness to interaction between surface and wheel was the basic criteria of evaluation from a safety point of view. The paper is oriented to the observation and evaluation of described parameters during realized simulations and experimental measurements. For simulations the dynamic characteristics of real vehicles were used.
\end{abstract}

KEY WORDS: Road serviceability, pavement, evenness, road safety, discomfort

\section{INTRODUCTION}

The Slovak Pavement Management System (PMS) is a tool for effectively dividing the budget for the management of road rehabilitation. The system includes processes for effective maintenance, repairs and the renewal of road surfaces and structures. The processes are based on the diagnostics of the pavement surface parameters (serviceability level of pavement) and bearing capacity. One of the most important input parameters into PMS is The Longitudinal unevenness - input by the International Roughness Index (IRI), describing the longitudinal unevenness quality in five levels.

In the next part of the paper correlations of internationally established dynamic quantifiers of longitudinal unevenness are presented. Following the ascertained correlations of parameter $\mathrm{C}$ and IRI (International Roughness Index) and new legal regulations the classification scale of IRI used in Slovakia has been modified.

\section{INTERNATIONAL ROUGHNESS INDEX - IRI}

Parameter IRI is obtained using the Reference Quarter Car Simulation (RQCS) according to (Sayers et al 1998) and Fig. 1. 
This mathematical model is defined mathematically by two second-order differential equations:

$$
\begin{aligned}
& \ddot{z}_{s} \cdot m_{s}+C_{s} \cdot\left(\dot{z}_{s}-\dot{z}_{u}\right)+k_{s} \cdot\left(z_{s}-z_{u}\right)=0 \\
& \ddot{z}_{s} \cdot m_{s}+m_{u} \cdot \ddot{z}_{u}+k_{t} \cdot z_{u}=k_{t} \cdot y
\end{aligned}
$$

We can express this system as:

$$
\begin{aligned}
& \ddot{z}_{s}+C \cdot\left(\dot{z}_{s}-\dot{z}_{u}\right)+k_{2} \cdot\left(z_{s}-z_{u}\right)=0 \\
& \ddot{z}_{s}+u \cdot \ddot{z}_{u}+k_{1} \cdot z_{u}=k_{1} \cdot y
\end{aligned}
$$

where:

$m_{S}, m_{u}$ - weight of the sprung mass and the unsprung mass

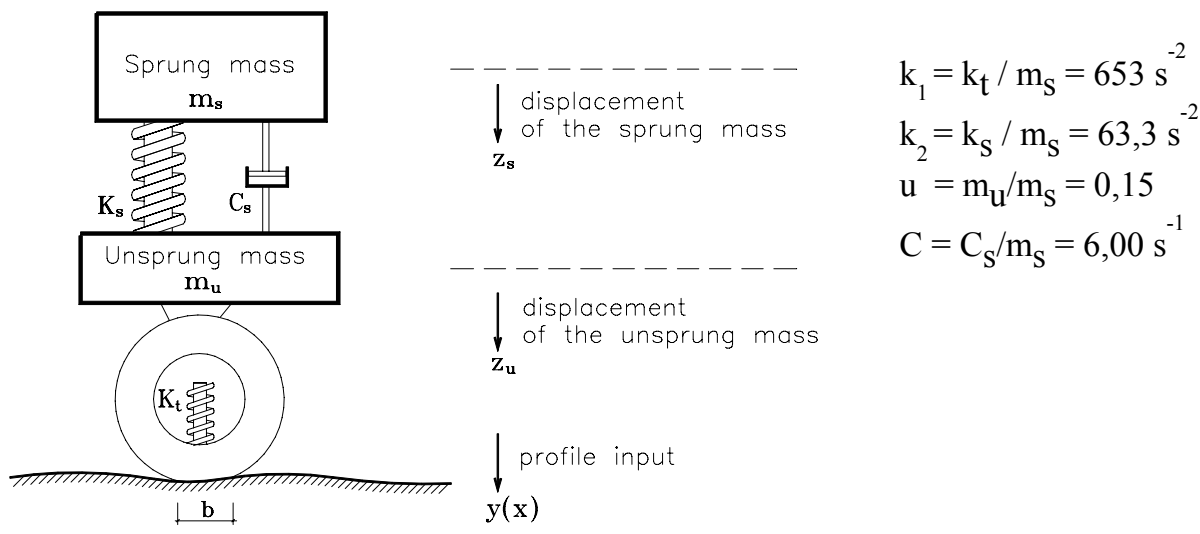

Figure1: The Reference Quarter Car Simulation

Equations (1) - (4) apply for temporal domain. We solve this model in the linear domain, we know the real longitudinal profile per $0.25 \mathrm{~m}$, whereupon we must find a vector of spatial derivations $-Z^{\mathrm{T}}(\mathrm{x})_{(\mathrm{i})}=\left(\mathrm{z}_{1 \mathrm{i}}, \mathrm{z}_{2 \mathrm{i}}, \mathrm{z}_{3 \mathrm{i}}, \mathrm{z}_{4 \mathrm{i}}\right)$. The values of this vector are calculated as:

$$
\begin{aligned}
& z_{s, i}^{\prime}=s_{11} \cdot z_{s, i-1}^{\prime}+s_{12} \cdot z_{s, i-1}^{\prime \prime}+s_{13} \cdot z_{u, i-1}^{\prime}+s_{14} \cdot z_{u, i-1}^{\prime \prime}+r_{1} \cdot y_{i}^{\prime} \\
& z_{s, i}^{\prime \prime}=s_{21} \cdot z_{s, i-1}^{\prime}+s_{22} \cdot z_{s, i-1}^{\prime \prime}+s_{23} \cdot z_{u, i-1}^{\prime}+s_{24} \cdot z_{u, i-1}^{\prime \prime}+r_{2} \cdot y_{i}^{\prime} \\
& z_{u, i}^{\prime}=s_{31} \cdot z_{s, i-1}^{\prime}+s_{32} \cdot z_{s, i-1}^{\prime \prime}+s_{33} \cdot z_{u, i-1}^{\prime}+s_{34} \cdot z_{u, i-1}^{\prime \prime}+r_{3} \cdot y_{i}^{\prime}
\end{aligned}
$$




$$
z_{u, i}^{\prime \prime}=s_{41} \cdot z_{s, i-1}^{\prime}+s_{42} \cdot z_{s, i-1}^{\prime \prime}+s_{43} \cdot z_{u, i-1}^{\prime}+s_{44} \cdot z_{u, i-1}^{\prime \prime}+r_{4} \cdot y_{i}^{\prime}
$$

The presented system can be expressed in the following matrix form:

$$
Z(x)_{(i)}=\underline{S} \cdot Z(x)_{(i-1)}+R \cdot y_{(i)}^{\prime}
$$

where:

$$
\begin{aligned}
& Z^{T}(x)_{(i)}=\left(\mathrm{z}_{1, \mathrm{i}} ; \mathrm{z}_{2, \mathrm{i}} ; \mathrm{z}_{3, \mathrm{i}} ; \mathrm{z}_{4, \mathrm{i}}\right)=\left(\mathrm{z}_{\mathrm{s}, \mathrm{i}}^{\prime} ; \mathrm{z}_{\mathrm{s}, \mathrm{i}}^{\prime \prime} ; \mathrm{z}_{\mathrm{u}, \mathrm{i}}^{\prime} ; \mathrm{z}_{\mathrm{u}, \mathrm{i}}^{\prime \prime}\right)
\end{aligned}
$$

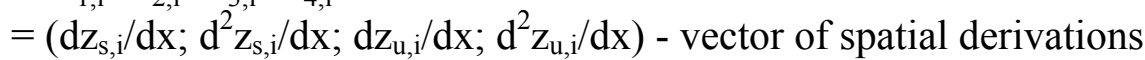

$$
\begin{aligned}
& \mathbf{S} \text { - state transition matrix } 4 \times 4 \text {, } \\
& \mathbf{R} \text { - partial response matrix } 1^{\mathrm{x}} 4 \\
& \mathrm{y}^{\prime}(\mathrm{i}) \text { - slope input } \\
& \mathrm{i} \text { - present step, } \mathrm{i}-1 \text { - previous time step }
\end{aligned}
$$

The differential equations (7) - (10) can be expressed in the following matrix form

$$
Z(t)=\underline{A} \cdot K(t)+B \cdot y(t)
$$

where:

$Z^{T}(t)=\left(\dot{z}_{s}, \ddot{z}_{s}, \dot{z}_{u}, \ddot{z}_{u}\right)=\left(\mathrm{dz}_{\mathrm{s}} / \mathrm{dt}, \mathrm{d}^{2} \mathrm{z}_{\mathrm{s}} / \mathrm{dt}, \mathrm{dz} \mathrm{z}_{\mathrm{u}} / \mathrm{dt}, \mathrm{d}^{2} \mathrm{z}_{\mathrm{u}} / \mathrm{dt}\right)$-vector of temporal derivations $K^{T}(t)=\left(z_{s}, \dot{z}_{s}, z_{u}, \dot{z}_{u}\right)$ - additive vector of temporal derivations

$$
\begin{aligned}
& \underline{A}=\left[\begin{array}{cccc}
0 & 1 & 0 & 0 \\
-K_{2} & -C & K_{2} & C \\
0 & 0 & 0 & 1 \\
K_{2} / u & C / u & -\left(K_{1}+K_{2}\right) / u & -C / u
\end{array}\right] \\
& B=\left[\begin{array}{c}
0 \\
0 \\
0 \\
K_{1} / u
\end{array}\right]
\end{aligned}
$$

For a constant length of the step, on which $\mathrm{y}^{\prime}(\mathrm{i})$ is a constant, the $\underline{\mathbf{S}}$ and $\mathbf{R}$ matrices can be computed from the $\underline{\mathbf{A}}$ and $\mathbf{B}$ matrices:

$$
\begin{aligned}
& \underline{S}=e^{\underline{A} \cdot d t} \\
& R=\underline{A}^{-1} \cdot(\underline{S}-\underline{I}) \cdot B
\end{aligned}
$$


where:

$$
d t(s)=\underline{d x}(m) / v(m / s)
$$

I- identity matrix $4 \times$

The algorithm for the evaluation of longitudinal unevenness - IRI KCS, according to the original methods (Sayers et al 1998), has been created in Microsoft Excel 97. This program carries out equations (1)-(15) and consists of the following steps:.

Calculation of profile slope input - the profile slope input is computed for every measuring point (we must known elevations of longitudinal profile per $0,25 \mathrm{~m}$ ):

$$
\mathbf{y}_{(\mathrm{i})}^{\prime}=\left(\mathbf{y}_{(\mathbf{i}-1)}-\mathbf{y}_{(\mathbf{i})}\right) / \mathbf{d x}, \quad \mathrm{i}=2,3, \ldots \ldots, \mathrm{N}
$$

where:

$\mathbf{y}_{\text {(i) }}^{\prime}$ - smoothed profile slope input

$\mathbf{y}_{(i)}$ - elevation of longitudinal profile $[\mathrm{m}]$

$\mathbf{d x}-$ measurement interval $\mathrm{dx}=\mathrm{b}=0,25 \mathrm{~m}$

Computation of the vector of spatial derivations $Z(x)_{(i)}$ - the computation of vector $\mathrm{Z}^{\mathrm{T}}(\mathrm{x})_{(\mathrm{i})}=\left(\mathrm{z}_{1, \mathrm{i}} ; \mathrm{z}_{2, \mathrm{i}} ; \mathrm{z}_{3, \mathrm{i}} ; \mathrm{z}_{4, \mathrm{i}}\right)=\left(\mathrm{z}_{\mathrm{s}, \mathrm{i}}^{\prime} ; \mathrm{z}_{\mathrm{s}, \mathrm{i}}^{\prime \prime} ; \mathrm{z}_{\mathrm{u}, \mathrm{i}}^{\prime} ; \mathrm{z}_{\mathrm{u}, \mathrm{i}}^{\prime \prime}\right)$ is realised by the equation (15):

$$
Z(x)_{(i)}=\underline{S} \cdot Z(x)_{(i-1)}+R \cdot y_{(i)}^{\prime}
$$

where :

$$
\begin{array}{ll}
\underline{\mathbf{S}}-\text { state transition matrix } 4 \times 4, & \mathbf{R}-\text { partial response matrix } 1^{\mathrm{x}} 4 \\
\mathrm{i}-\text { present step, } & \mathrm{i}-1-\text { previous time step }
\end{array}
$$

Determination of the corrected profile slope

$$
\mathrm{T}_{\mathrm{i}}=\left(\mathrm{z}_{3 \mathrm{i}}-\mathrm{z}_{1 \mathrm{i}}\right), \quad \mathrm{i}=2,3, \ldots, \mathrm{N}
$$
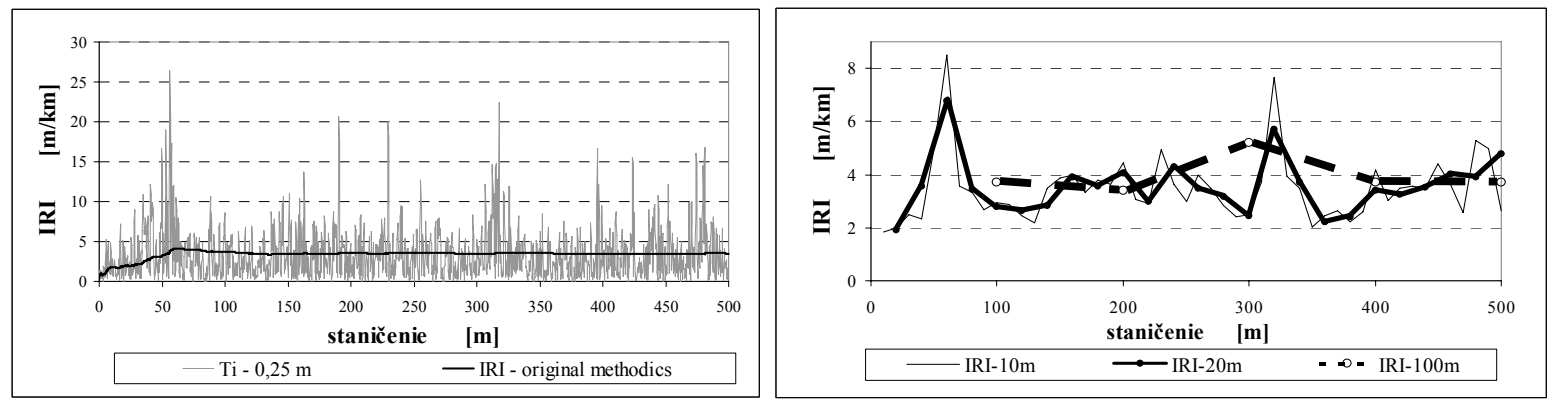

Figure2: Corrected profile slope per $0,25 \mathrm{~m}$ and original parameter IRI (left) and IRI appreciated for window 10,20 and $100 \mathrm{~m}$ (right) 
Calculation of the parameter IRI - IRI represents arithmetic average of the corrected slope. Values of parameter IRI can be appreciated for a window of a discretionary length (conveniently 1, 10, 20, $100 \mathrm{~m}$ - Fig.2 right).

$$
\operatorname{IRI}=\frac{1}{N-1} \cdot \sum_{i=2}^{N} T_{i}
$$

\section{POWER SPECTRAL DENSITY OF LONGITUDINAL UNEVENNESS}

The discretionary evaluated road sections, which are homogenous from the point of view of construction and degradation conditions, can be evaluated through the medium theory of a stationary random process. This type of random process can be best characterized by a correlation function or power spectral density (PSD). The correlation function $K_{h}(\lambda)$ for this type of process is expressed in the linear domain with the equation

$$
K_{h}(\lambda)=\int_{-\infty}^{\infty} \int_{-\infty}^{\infty}\left[h_{1}(l)-E_{h}\right] \cdot\left[h_{2}(l-\lambda)-E_{h}\right] \cdot f_{2}\left(h_{1}, h_{2}\right) d h_{1} \cdot d h_{2}
$$

where:

$$
\begin{array}{lll}
\lambda & - & \text { linear lag }[\mathrm{m}], \\
E_{h} & - & \text { expected value of stochastic unevenness; } E_{h}=0, \\
h(l) & - & \text { stochastic unevenness, } \\
f_{2}\left(h_{1}, h_{2}\right) & \text { - combination density of expectation. }
\end{array}
$$

Stochastic unevenness is computed as the difference between a real and theoretical profile. In our case we must identify elevations of longitudinal profile per $0.25 \mathrm{~m}$ and longitudinal unevenness are evaluated through the standardized correlation function $\rho_{h}(\lambda)$ (left hand side of Fig.3).

$$
\rho_{h}(\lambda)=K_{h}(\lambda) / D_{h}
$$
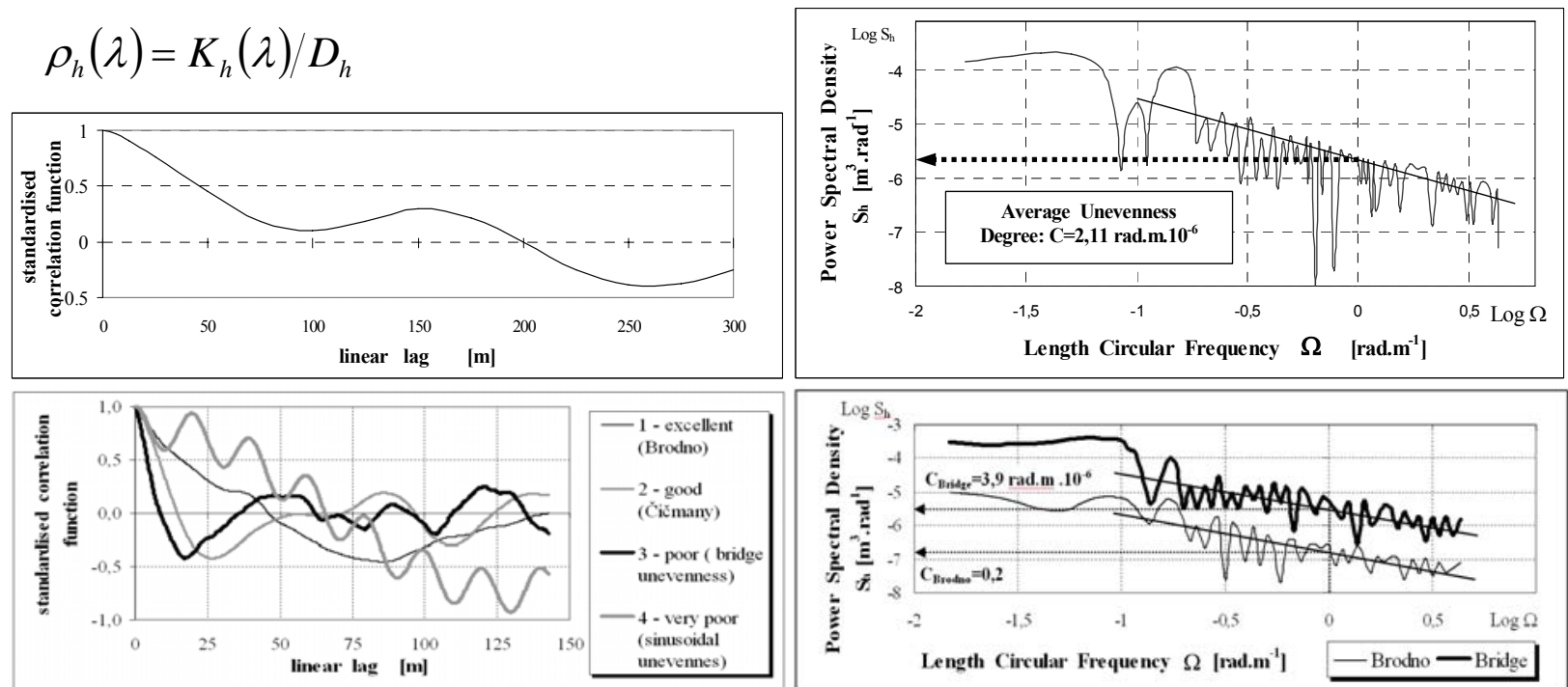

Figure3: Standardized correlation function and PSD of stochastic unevenness 
For the purpose of unevenness assessment it is more appropriate to use power spectral density (PSD) $S_{h}(\Omega)$ (right hand side of Fig.3), which can be expressed from the correlation function by means of Wiener Chinchine equation:

$$
S_{h}(\Omega)=2 / \pi \cdot \int_{0}^{\infty} K_{h}(\lambda) \cdot \cos (\Omega \lambda) \cdot d \lambda
$$

where:

$\begin{array}{llll}D_{h} & - & \text { dispersion of an stochastic unevenness } & {\left[\mathrm{m}^{2}\right],} \\ \Omega & - & \text { angular spatial frequency } & {\left[\mathrm{rad} . \mathrm{m}^{-1}\right],}\end{array}$

$$
\Omega=2 \cdot \pi / L
$$

$$
L \quad-\quad \text { unevenness wavelength } \quad[\mathrm{m}] \text {. }
$$

The unevenness degree $C$ [rad.m.10 $\left.0^{-6}\right]$ of an evaluated road section is expressed from the basic relation that was modified for our mode of unevenness identification by JP VŠDS.

$$
C=\frac{D_{y}}{I \cdot \frac{1}{N} \sum_{i=1}^{n} v_{i}}
$$

where:
$D_{y} \quad$-dispersion of sprung mass acceleration - left hand side of Fig.4 $\left[\mathrm{m}^{2} . \mathrm{s}^{-4}\right]$
I - - parameter of dynamic transfer
C $\quad$-unevenness degree - right hand side of Fig.4 $\left[\mathrm{rad}^{-1} \cdot \mathrm{s}^{-3}\right]$ [rad.m]
$v_{i} \quad$-digital values of a measured velocity - right hand side of Fig.4 [m.s $\left.{ }^{-1}\right]$
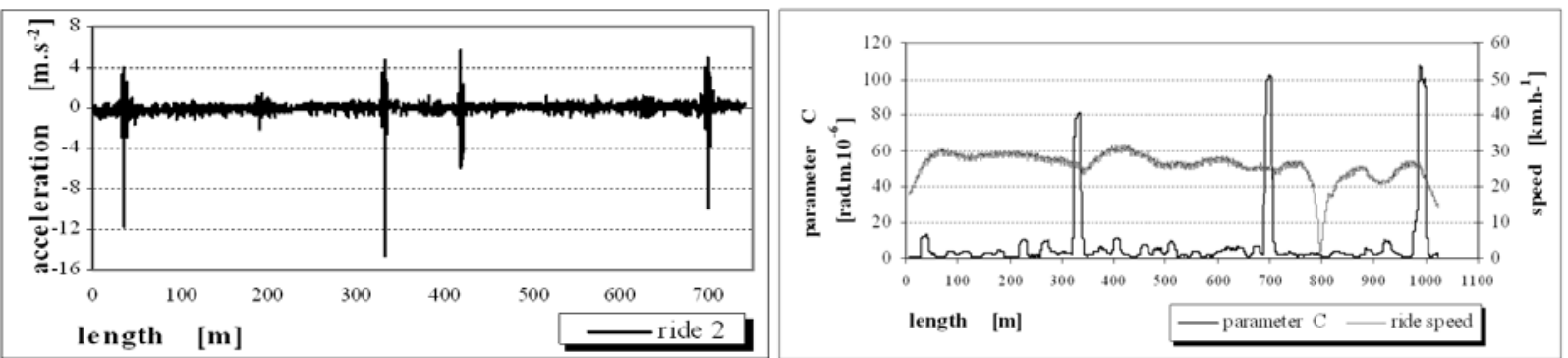

Figure4: Vertical acceleration indicated by speed control bump and ride speed (left hand side of Fig.4) and parameter C evaluated by JP VŠDS 


\section{THE CRITERIA OF UNEVENNESS EVALUATION BY IRI}

The criteria are base on described theoretical principles, and on the request of traffic safety and ride comfort assurance. The ride comfort described by the vertical acceleration of sprung mass of vehicle $a_{z}$ and the safety described by vertical dynamic strength $F_{z}$ on the contact of the wheel with pavement surface are described next. The simulation of the crossing of a half car model on generated harmonized unevenness as a random unevenness on real roads, measured by Profilograph GE, were realized for the determination of the relation between longitudinal unevenness and ride comfort (safety, respectively). The values of maximal acceleration of the vehicle body characterizing ride discomfort occasioned by unevenness were compared according to the Slovak standard STN ISO 2631-1.

The calculations and simulations were executed by use of the special software developed in the University of Zilina (Celko et al 2000) and with the CarSim Education program developed in the University of Michigan. The vehicle parameters correspond to the Skoda Felicia car, which is widespread in Slovakia.

The response depended on the amplitude and wavelength of three ride speeds which were detected for harmonized unevenness generated by simulation and described by IRI. Three maximal speeds permitted on the Slovak roads were used. The results for speed $90 \mathrm{kph}$ will be described. From Fig.5 it is definite which wavelength activated the maximal oscillation of the vehicle. These are the wavelengths that are the most unfavourable for passenger comfort. For the declared vehicle and a speed of $90 \mathrm{kph}$, it is $2.3 \mathrm{~m}$ and $18 \mathrm{~m}$. For $60 \mathrm{kph}$ speed, it is $2.1 \mathrm{~m}$ and $12 \mathrm{~m}$ and for $130 \mathrm{kph}$ speed $3.3 \mathrm{~m}$ and $27 \mathrm{~m}$. The model response on the harmonized unevenness is linearly dependant on the amplitude value. The relation between vehicle response and IRI was evaluated next. The relation between acceleration $a_{z}$ and IRI, correspondingly presented with wavelengths with amplitude $A=1 \mathrm{~cm}$ and speed $90 \mathrm{kph}$ are shown in Fig.6.

$90 \mathrm{~km} / \mathrm{h}$

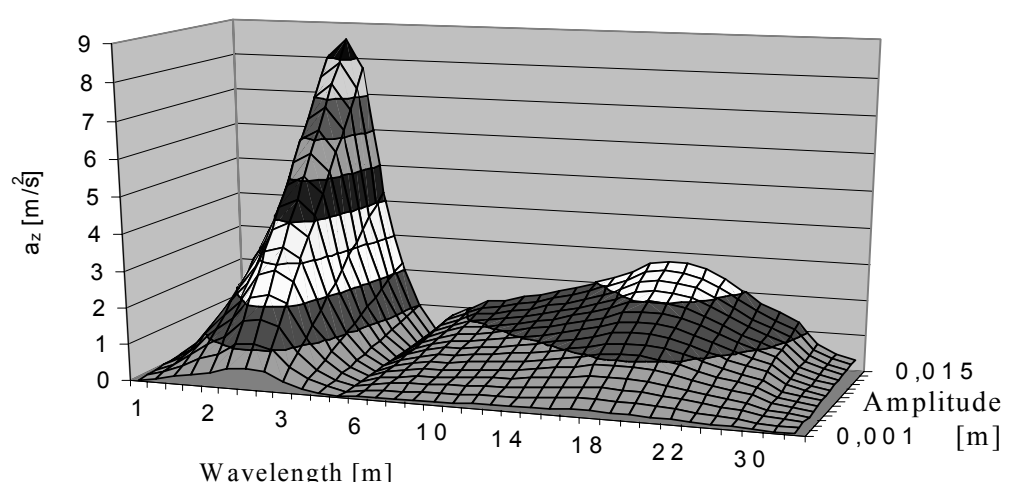

Figure5: The dependency between acceleration, wavelengths and amplitudes for $90 \mathrm{kph}$ speed

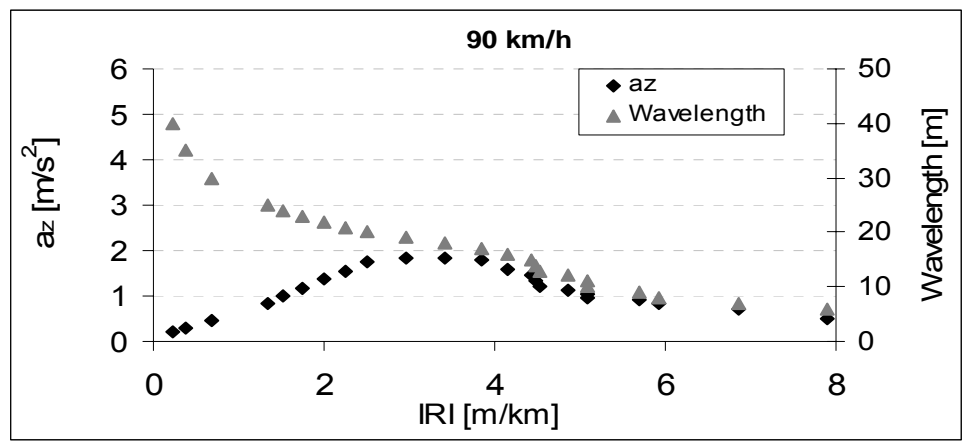

Figure6: The dependency between acceleration, wavelength, and IRI for $90 \mathrm{~km} / \mathrm{h}$ speed 
Following this analysis we can claim the values of the vehicle body acceleration increases with the growing of IRI only to specific point. This point corresponds to specific wavelengths dependant on the speed. A decreasing tendency despite the IRI increasing was observed after this point. On Fig. 7 these relations are extensive about the next points, with responsive higher amplitudes.

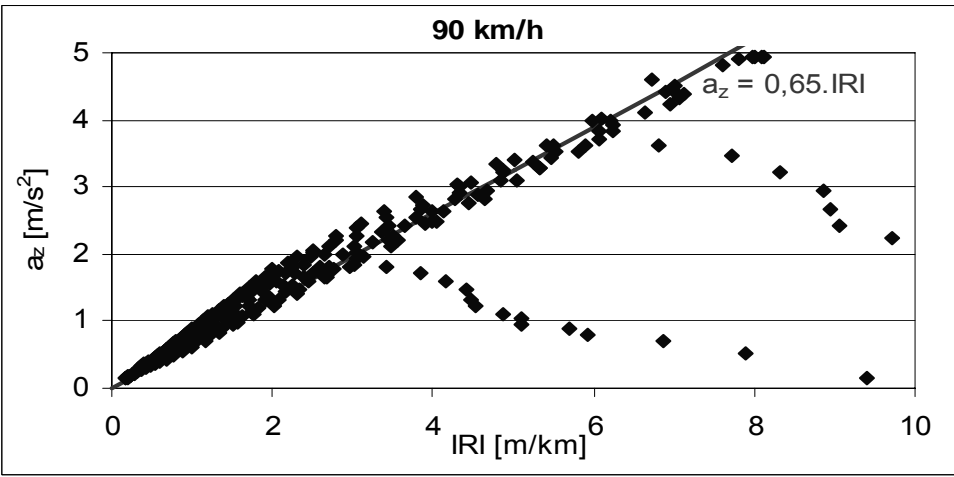

Figure7: The relation of acceleration on IRI for $90 \mathrm{kph}$

On Fig.7 these relations are extensive about the next points, with responsive higher amplitudes. The relation tendency shows a basic trend of points that delimited an area of maximal discomfort by minimal IRI values. The line by basic points group was interleaved for determination of the relation between IRI and $\mathrm{a}_{\mathrm{z}}$. The other points lying below the tendency are irrelevant from a comfort evaluation point of view. The upper values of IRI respond to the lower values of the response. The points above this group (of a speed of $60 \mathrm{kph}$ ) respond to the great wavelengths (more than $30 \mathrm{~m}$ ), which do not exist on the roads with a maximal speed of $60 \mathrm{kph}$. Therefore, we can ignore them. Fig.7 shows a determined relation between IRI and vehicle response characterized by vertical acceleration $a_{z}$, found from a fitted line equation of a basic tendency of the points.

The points outside of the basic tendency confirm that an equal value of IRI can describe more unevenness evocated different response. These points have identical amplitude but different wavelength, which means a lower value of acceleration for a higher IRI. It is also visible that during high speeds a shining oscillation of the vehicle origins for a low IRI value. This fact is determined by an overvaluation of the short wavelengths and undervaluation of the longer wavelengths by reference model of a car quarter. In addition, IRI is calculated for the speed $80 \mathrm{kph}$, so for higher speeds the differences are greater (Fig.8). However, we must take into consideration that the simulation was realized for the harmonic unevenness that occurs in real conditions in a minimal range.
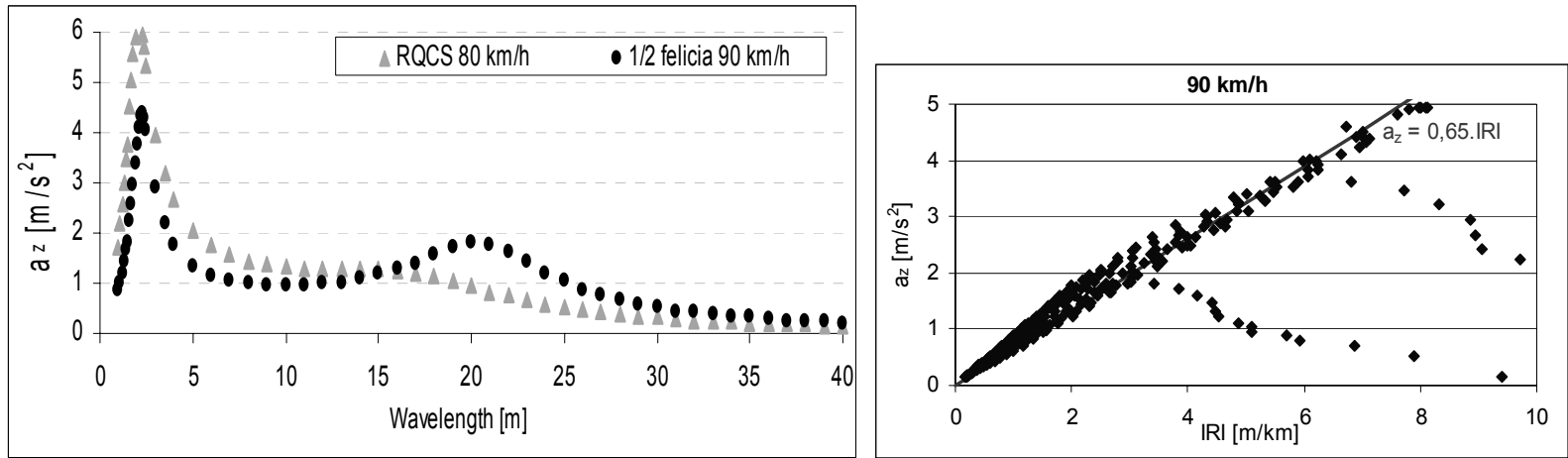

Figure 8: The comparison of response for different speeds of reference and real model 
According to the obtained relations, the scale of IRI evaluation depends on the safety and comfort was analyzed. The results show that a critical rank of evaluation of real response to unevenness is wavelengths corresponding with resonant frequency of a car's unsprung mass. The reference model declares lower values of acceleration of the sprung mass as a real car model. The values are two times more for the speed $90 \mathrm{kph}$ and four times more for the speed $130 \mathrm{kph}$. Depending on the analysis of the harmonic unevenness, the simulations realized on the real road sections were taken into account for design of the IRI classification scale.

The important characteristic of ride safety from the point of view of longitudinal unevenness is the vertical strength $\mathrm{F}_{\mathrm{z}}$ on the contact between vehicle and surface. The moment of minimal value was observed. The determined relation is presented on Fig.9.

The strength $\mathrm{F}_{z}$ has a decreasing tendency with an increasing of IRI. The different values of $F_{z}$ for identical IRI values are possible to achieve alike for acceleration. During simulation of harmonic unevenness and the speed of $60 \mathrm{kph}$ loss of contact does not occur. On the other hand, during speeds of $90 \mathrm{kph}$ and $130 \mathrm{kph} \mathrm{F}_{\mathrm{z}}$ achieved the zero value yet for low IRI values. The danger is not only a loss of contact but a low intensity of $\mathrm{F}_{\mathrm{z}}$, too. An intensity of the vertical strength has an influence on the stability of a car in a horizontal curve and on the breaking distance, too. The differences are determined by the characteristics of the reference model. In this case, the generally valid relation is not possible to establish because each vehicle has different weight and so also a different press strength of axle to road surface.

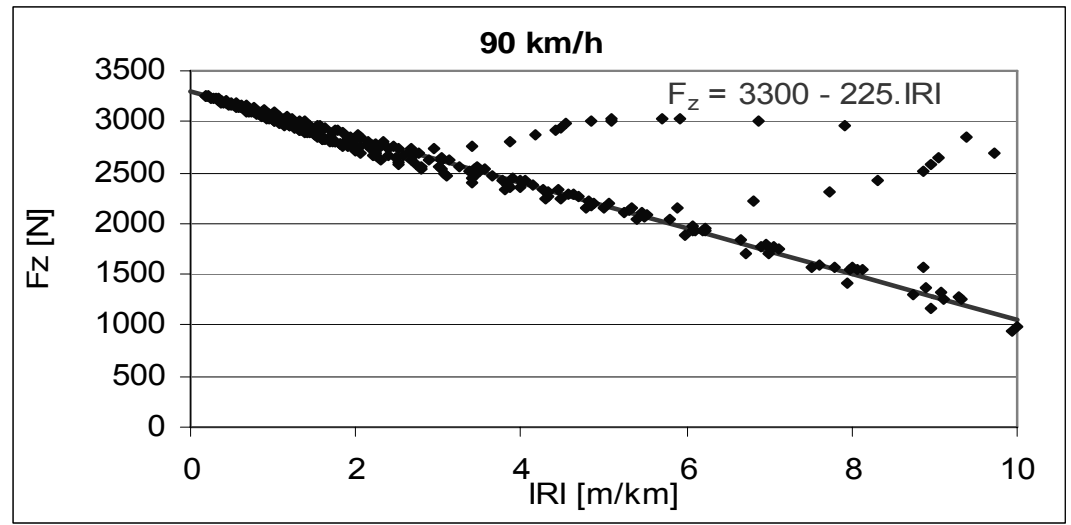

Figure9: The dependency of dynamic strength $F_{z}$ on IRI for the speed $90 \mathrm{~km} / \mathrm{h}$

Dependant on the presented results the new classification scale for IRI evaluation in the frame of Slovak PMS was proposed (Table 1).

Table 1: The proposal of classification scale of IRI

\begin{tabular}{|c|c|c|c|}
\hline \multirow{2}{*}{ Classification scale } & \multicolumn{3}{|c|}{ IRI [m/km] } \\
\cline { 2 - 4 } & Urban roads & Roads & Highways and expressways \\
\hline $\mathbf{1}$ & $<5$ & $<4$ & $<3$ \\
\hline $\mathbf{2}$ & $5-10$ & $4-8$ & $3-6$ \\
\hline $\mathbf{3}$ & $>10$ & $>8$ & $>6$ \\
\hline
\end{tabular}




\section{CONCLUSIONS}

The presented results are based on data samples that contain real conditions. The research activity on problems of the interaction between vehicle and surface continues. The analyses of unevenness and skid resistance are in the process of improving results. The verification of the models is verified by next measurements and simulations. The aim of the research is the generalization of the relation between IRI and vehicle response.

\section{REFERENCES}

CELKO, J. et al: Surface properties of the pavements (in Slovak), Scientific monograph. EDIS Zilina, 2000, ISBN 80-7100-774-9.

SAYERS, M. W. et al: The International Road Roughness Experiment (IRRE): Establishing correlation and calibration standard for measurements, World Bank, Techn. Paper, No. 45.

CEBON, D.: Handbook of vehicle-road interaction. Swets\&Zeitlinger, 1999, 612 pp.

SUN L.: Developing spectrum-based models for International Roughness Index and Present Serviceability Index. In: ASCE: Journal of Transportation Engineering Vol. 127, No. 6, 2001, ISSN: 0733-947X pp. 463 - 470. 